\title{
CLINICAL STUDY OF ABSENCE OF THE PALMARIS LONGUS AND ITS CORRELATION WITH OTHER ANATOMICAL ANOMALIES
}

\section{Sukre Shivaji B ${ }^{1}$, Kawale Deepak N ${ }^{* 2}$.}

${ }^{1}$ Professor and Head, Department of Anatomy, Government Medical College, Aurangabad, Maharashtra, India.

${ }^{* 2}$ Assistant Professor, Department of Anatomy, Government Medical College, Aurangabad, Maharashtra, India.

\section{ABSTRACT}

Introduction: Palmaris longus $(\mathrm{PL})$ is a muscle with a long tendon which is very useful in reconstructive surgery. It is well known that individuals may have unilateral or bilateral absence of palmaris longus.

Aim \& Objective: The aim of this study was to evaluate the incidence of unilateral and bilateral absence of palmaris longus in study population.

Materials and Methods: The presence of the PL was clinically tested in 1000 normal medical students both male and female using the various standard techniques. In those students showing agenesis of PL other 4 separate tests were performed to confirmation of agenesis.

Results: The overall prevalence of the absence of PL was $16.2 \%$. All techniques were equally effective in determining the absence of the PL. out of $162 \mathrm{PL}$ agenesis 138 were females (27.6\%) and 24 were males (4.8\%). Unilateral agenesis was seen in $76(15.2 \%)$ and bilateral in $86(17.2 \%)$ subjects. The left-side agenesis was seen in 52 females $(53.06 \%)$ and 46 males $(46.93 \%)$ with the total of $98(60.49 \%)$ subjects. The right-side agenesis was observed in 64 (39.5\%) subjects; of which 41 (64.06\%) were females and 23 (35.93\%) were males. Out of 86 bilateral agenesis 51 (59.3\%) were females and 35 (40.69\%) were males.There was no significant difference in its absence with regard to the body side or sex.

Conclusions: There is no statistical association between the PL agenesis and gender, handedness, body sides and associated anomalies like absence of FDS to little finger, incomplete SPA in the studied population. Nearly all techniques of examining for the absence of the PL are equally effective but the method suggested by Mishra is quiet the better as it was easily understood by subjects and can be used even when thumb abduction is not possible.

KEY WORDS: Absence, Unilateral, Bilateral, Palmaris Longus.

Address for Correspondence: Dr. Kawale Deepak N. Assistant Professor, Department of Anatomy, Government Medical College, Aurangabad, Maharashtra, India. E-Mail: kawale.deepak@gmail.com

\begin{tabular}{|c|c|c|}
\hline \multicolumn{3}{|c|}{ Access this Article online } \\
\hline \multirow{3}{*}{ Quick Response code } & \multicolumn{2}{|c|}{$\begin{array}{l}\text { Web site: International Journal of Anatomy and Research } \\
\text { ISSN 2321-4287 } \\
\text { www.ijmhr.org/ijar.htm }\end{array}$} \\
\hline & $\begin{array}{l}\text { Received: } 16 \text { Jan } 2017 \\
\text { Peer Review: } 20 \text { Jan } 2017 \\
\text { Revised: None }\end{array}$ & $\begin{array}{l}\text { Accepted: } 24 \text { Feb } 2017 \\
\text { Published (O): } 31 \text { Mar } 2017 \\
\text { Published (P): } 31 \text { Mar } 2017\end{array}$ \\
\hline & Revised: ivone & 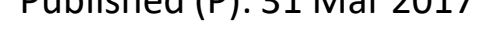 \\
\hline
\end{tabular}

\section{INTRODUCTION}

Palmaris longus muscle is one of the superficial flexor muscles of the forearm. It is a slender muscle that acts on the skin and distal digital webs. It arises from common flexor tendon of humerus, from the intramuscular septa between it and the adjacent muscles, and from the antebrachial fascia [1-4]. It ends in a slender, flattened tendon, which passes distally lying on the medial side of the flexor carpi radialis [4]. 
The PL muscle may be tendentious above and muscular below or opposite to this, it may be present as central tendon in between two muscle bundles, may consist solely tendentious band only. Muscle may be double or absent on one or both side in body. PL muscle is fully developed at birth. In a sequence of phylogenic developement palmaris longus is classified as a degenerating metacarpophalangeal joint flexor muscle and also described as one of the most variable muscles in our body [4]. Palmaris longus oftenly used as graft in various reconstructive surgeries. Palmaris longus is considered to be a superfluous tendon because its absence does not significantly affect the function of the wrist. It is therefore very useful in orthopaedic, hand and reconstructive surgery, management of facial palsies, lip augmentation, ptosis reconstruction, restoration of lip and chin defects $[6,7]$. Most standard textbooks of hand surgery quote the prevalence of absence of palmaris longus at around $15 \%$. However, this figure varies considerably in different ethnicgroups. The aim of this study was to evaluate the incidence of unilateral and bilateral absence of palmaris longus in study population.

\section{MATERIALS AND METHODS}

Study group includes of 1000 first year medical, dental and paramedical students ( 500 boys and 500 girls) from Government Medical College, Aurangabad, Maharashtra, India. Subjects under study having any deformities or injury in the upper extremity were excluded from the present study. In this present study, the prevalence of presence or absence of PL was decided by multiple of tendon examination techniques described by Thompson's fist,Schaeffer's test, Mishra's $1^{\text {st }} \& 2^{\text {nd }}$ test, Pushpa kumar's two finger test.

If present, medial to tendon of flexor carpi radialis in the middle of the lower part of the front of forearm PL appears as a prominent tendon, just above the wrist. If it is not seen clearly, a slight extending force was applied with the help of palm of other hand to the middle three fingers. If it is not visible it was taken as absent in that particular subject. The results were statistically analyzed by SPSS statistical software.
Thompson's test: At first the subject is asked to make a fist, then flex the wrist and finally the thumb is opposed and flexed over the fingers.

Standard test (Schaeffer's test): In this test subject is asked to oppose the thumb to the little finger and then flex the wrist.

Mishra's test I: The metacarpo-phalangeal joints of all fingers are passively hyperextended by the examiner and the subject is asked to actively flex the wrist.

Mishra's test II: The subject is asked to abduct the thumb against resistance with the wrist in slight palmar flexion.

Pushpa kumara's two finger sign method: Index and middle fingers are fully extended and wrist and other fingers are flexed and finally thumb is fully opposed and flexed.

All these tests make the Palmaris longus tendon prominent so that it can be easily detected on the flexor aspect of wrist [4].

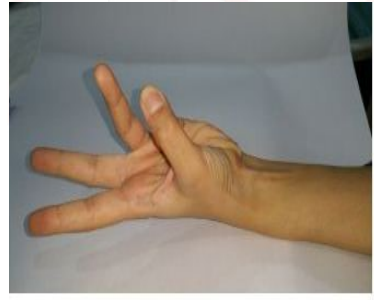

Fig.1: Schaeffer's technique

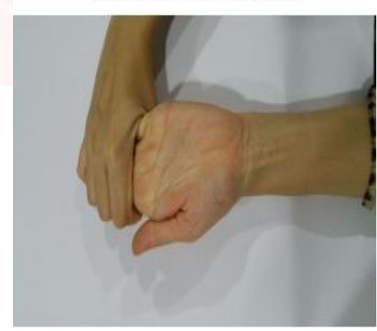

Fig. 3 : Mishra's first test

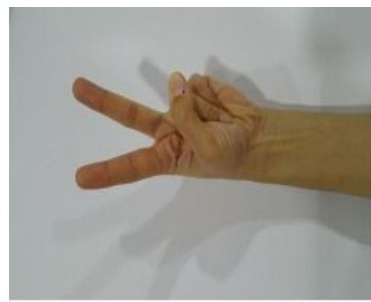

Fig. 5 : Pushpakumar's two finger sign method.

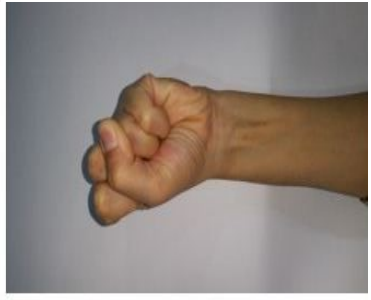

Fig.2: Thompson's technique

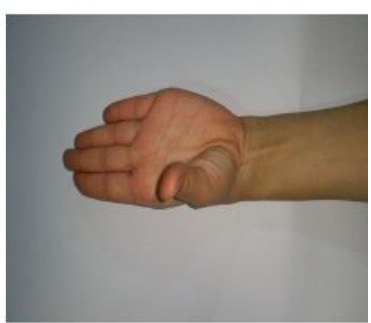

Fig.4 : Mishra's second test

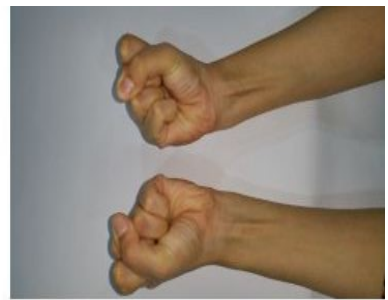

Fig.6: Thompson's fist test

\section{RESULTS}

In a sample of 1000 medical faculty students (500 males and 500 females), a total of $162 \mathrm{PL}$ agenesis was seen of which 138 were females $(27.6 \%)$ and 24 were males (4.8\%). Unilateral agenesis was seen in $76(15.2 \%)$ and bilateral 
in $86(17.2 \%)$ subjects. The left-side agenesis was seen in 52 females (53.06\%) and 46 males $(46.93 \%)$ with the total of $98(60.49 \%)$ subjects. The right-side agenesis was observed in 64 (39.5\%) subjects; of which 41 (64.06\%) were females and 23 (35.93\%) were males. Out of 86 bilateral agenesis 51 (59.3\%) were females and 35 (40.69\%) were males.

Table 1: Showing the agenesis of the palmaris longus.

\begin{tabular}{|c|c|c|c|c|c|c|}
\hline GENDER & AGENESIS & $\begin{array}{c}\text { NO } \\
\text { AGENESIS }\end{array}$ & $\begin{array}{c}\text { UNILATERAL } \\
\text { AGENESIS }\end{array}$ & $\begin{array}{c}\text { BILATERAL } \\
\text { AGENESIS }\end{array}$ & $\begin{array}{c}\text { LEFT SIDED } \\
\text { AGENESIS }\end{array}$ & $\begin{array}{c}\text { RIGHT SIDED } \\
\text { AGENESIS }\end{array}$ \\
\hline MALE & 24 & 476 & $31(40.78 \%)$ & $51(59.3 \%)$ & $46(46.93 \%)$ & $23(35.93 \%)$ \\
\hline FEMALE & 138 & 362 & $45(59.21 \%)$ & $35(40.69 \%)$ & $52(53.06 \%)$ & $41(64.06 \%)$ \\
\hline TOTAL & 162 & 838 & $76(15.2 \%)$ & $86(17.2 \%)$ & $98(60.49 \%)$ & $64(39.5 \%)$ \\
\hline
\end{tabular}

\section{DISCUSSION}

The predominance of PL agenesis was observed to be $17.2 \%$ ( $8 \%$ bilateral and $9.2 \%$ one-sided). The prevalence is common on left side. Male subjects had a more noteworthy probability of one-sided agenesis, while female subjects were shown to have bilateral agenesis [2]. Usually in many reconstructive surgeries tendon of hand is used. Palmaris longus tendon meets the required criteria such as length, diameter and availability and along with no any functional deformity which makes it ideal choice for surgeons in reconstructive surgeries. ${ }^{3}$ The palmaris longus tendon is regularly viewed as the perfect graft for substitution of the long flexors of the fingers, and of the flexor pollicis longus tendon [5].

Wehbe $M$ and Bryn $M$ reported $70-85 \%$ presence of PL muscle.Few authors concluded that apart from its ethnic varieties, its bilateral absence is more common in females as compares to males, and if there is unilateral absence then more common on the left side [6].

In vertebrates it is discovered just in warm blooded creatures and is best created in those where the forelimb is utilized for ambulation. ${ }^{8}$ In humans beings the absence of palmaris longus either unilateral or bilateral seems to be hereditary but its genetic transmission is not clear [10].

In present study Clinical testing revealed an incidence of unilateral absence of PL is $15.2 \%$ and a bilateral absence of PL is $17.2 \%$. We found that females have a higher incidence of both bilateral and unilateral absence of PL also left sided agenesis is seems to be more common than right side. No significant statistical difference was found between absences of PL and gender or body side [11].

It is observed that the overall results from various previous studies by different authors regarding agenesis of PL bilateral absence occurs in $8 \%$ to $16 \%$ of individuals, with unilateral absence occurring in $4 \%$ to $14 \%$.While in most of the standard textbooks of hand surgery stated that prevalence of absence of $\mathrm{PL}$ is around 15\% [12].

The prevalence of absence of PL in the Chinese populace was $4.6 \%$ (bilateral $1.2 \%$ and unilateral 3.3\%) [13]. While the prevalence of absence of PL on both unilaterally and bilaterally was $26.6 \%$ in Turkish subjects. In Nigerians the overall agenesis of PL was $0.17 \%$ with one-sided agenesis in males was more commonly involved [15]. Among Nigerian populace, $31.25 \%$ subjects showed absence of PL, out of which $12.5 \%$ was recorded as unilateral absence while and $18.75 \%$ subjects recorded as bilateral absence of PL $[16,17]$. While many previous studies have conflicted with respect to the frequency of PL absence in connection to body side and gender [18-20].

\section{CONCLUSION}

In study population, palmaris longus is absent unilaterally in $15.2 \%$ and bilaterally in $17.2 \%$ of population with an overall absence of $16.2 \%$.Showing nearly similar rate to Caucasians which varies from $14-18 \%$. While Malays had a prevalence of palmaris longus absence at $11.3 \%$ followed closely by the Indians at $10.7 \%$ and the Chinese had the lowest absence rate of $6.0 \%$. Agenesis of palmaris longus more frequently on the left than the right and slightly more frequently in females than males and also the bilateral agenesis is more common than unilateral agenesis.

\section{Conflicts of Interests: None}

\section{REFERENCES}

[1]. Troha F, Baibak G J, Kelleher J C. Frequency of the palmaris longus tendon in North American caucasians.Ann Plast Surg 1990;25:477-8.

[2]. Vanderhooft E. The frequency and relationship between the palmaris longus and plantaris tendons.Am J Orthop 1996;25:38-41. 
[3]. Reimann A F, Daseler E H, Anson B J, Beaton L E.The palmaris longus muscle and tendon; a study of 1600 extremeties. Anat Rec 1944;89:495-505.

[4]. Tountas CP, Bergman RA. Anatomic Variations of the Upper Extremity.New York: Churchill Livingstone, 1993:141-3.

[5]. Schaeffer JP. On the variations of the palmaris longus muscle. Anat Rec1909;3:275-8.

[6]. Wehbe MA. Tendon graft donor sites. J Hand Surg (Am) 1992;17:1130-2.

[7]. Reimann AF, Daseler EH, Anson BJ, Beaton LE. The palmaris longus muscle and tendon; a study of 1600 extremities. Anat Rec 1944;89:495-505.

[8]. Ceyhan O, Mavt A. Distribution of agenesis of the palmaris longus muscle in 12-18 years old age groups. Indian J Med Sci 1997;51:156-60.

[9]. Thompson NW, Mockford BJ, Rasheed T, Herbert KJ. Functional absence of the flexor digitorum superficialis to the little finger and absence of the palmaris longus - is there a link? J Hand Surg (Br) 2002;7:433-4.

[10]. O'Sullivan E, Mitchell BS. Association of the absence of the palmaris longus tendon with an anomalous superficial palmar arch in the human hand. J Anat 2002;201:405-8. Erratum in: J Anat 2003;202:253.

[11]. Harvey JF, Chu G, Harvey PM. Surgical availability of the plantaris tendon. J Hand Surg (Am) 1983;8:243-7.

[12]. Thompson JW, McBatts J, Danforth CH. Hereditary and racial variations in the musculus palmaris longus. Am J Phys Anthrop 1921;4:205-20.
[13].Machado AB, DiDio LJ. Frequency of the musculus palmaris longus studied in vivo in some Amazon Indians. Am J Phys Anthrop 1967;27:11-20.

[14]. Troha R, Baibak GJ, Kelleher JC. Frequency of the palmaris longus tendon in North American Caucasians. Ann Plast Surg 1990;25:477-8.

[15]. Thompson NW, Mockford BF, Cran GW. Absence of the palmaris longus muscle: a population study. Ulster Med J 2001;70:22-4.

[16]. Ito MM, Aiko M, Kida MY, Ishii S, Kumaki K, Tanaka $S$. Length and width of the tendinous portion of the palmaris longus: a cadaver study of adult Japanese. J Hand Surg (Am) 2001;26:706-10.

[17]. George R. Co-incidence of the palmaris longus and plantaris muscles. Anat Rec 1953;116:521-3.

[18]. Baker DS, Gaul JS, Williams VK, Graves M. The little finger superficialis - clinical investigation of its anatomic and functional shortcomings. J Hand Surg (Am) 1981;6:374-8.

[19]. Mishra S. Alternative tests in demonstrating the presence of palmaris longus. Indian J Plast Surg 2001;34:12.

[20]. Vanderhooft E. The frequency and relationship between the palmaris longus and plantaris tendons. Am J Orthop 1996;25:38-41.

[21]. Pushpakumar SB, Hanson RP, Carroll S. The 'two finger' sign. Clinical examination of palmaris longus (PL) tendon. Br J Plast Surg.2004;57:184-5.

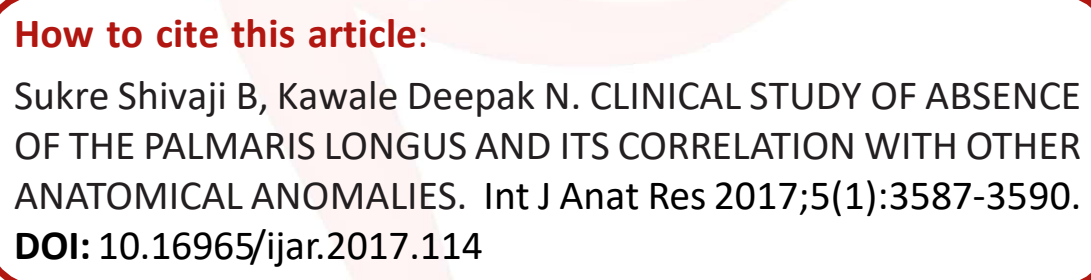

